\title{
In vivo and ex vivo effects of propofol on myocardial performance in rats with obstructive jaundice
}

\author{
Hong-Mei Ren ${ }^{1 \dagger}$, Li-Qun Yang ${ }^{2 \dagger}$, Zhi-Qiang Liu ${ }^{3+}$, Cai-Yang Chen ${ }^{2}$, Chi-Wai Cheung ${ }^{4}$, Kun-Ming Tao ${ }^{2}$, \\ Jian-Gang Song ${ }^{2}$, Wu-Rong Chen ${ }^{1}$ and Wei-Feng $\mathrm{Yu}^{2^{*}}$
}

\begin{abstract}
Background: Responsiveness of the "jaundiced heart" to propofol is not completely understood. The purpose of this study was to evaluate the effect of propofol on myocardial performance in rats with obstructive jaundice.

Methods: Male Sprague-Dawley rats $(n=40)$ were randomly allocated into two groups, twenty underwent bile duct ligation (BDL), and 20 underwent a sham operation. Seven days after the surgery, propofol was administered in vivo and ex vivo (Langendorff preparations). Heart rate, left ventricular end-systolic pressure (LVESP) left ventricular enddiastolic pressure (LVEDP), and maximal rate for left ventricular pressure rise and decline $\left( \pm \mathrm{dP} / \mathrm{dt}_{\max }\right)$ were measured to determine the influence of propofol on the cardiac function of rats.

Results: Impaired basal cardiac function was observed in the isolated BDL hearts, whereas in vivo indices of basal cardiac function (LVESP and $\pm \mathrm{dP} / \mathrm{dt}$ ) in vivo were significantly higher in rats that underwent BDL compared with controls. With low or intermediate concentrations of propofol, these indices of cardiac function were within the normal physiologic range in both groups, and responsiveness to propofol was unaffected by BDL. When the highest concentration of propofol was administrated, a significant decline in cardiac function was observed in the BDL group.

Conclusions: In rats that underwent BDL, basal cardiac performance was better in vivo and worse ex vivo compared with controls. Low and intermediate concentrations of propofol did not appear to impair cardiac function in rats with obstructive jaundice.
\end{abstract}

\section{Background}

Postoperative obstructive jaundice is associated with multiple organ dysfunction syndrome [1-3]. Specifically, the cardiovascular instability caused by defects in myocardial performance and vascular reactivity is thought to be an important mechanism in the pathophysiology of multiple organ dysfunction syndrome [4,5]. In 1986, Green [5] reported impaired left ventricular performance in dogs with cholemia, and called this hepatic cardiomyopathy "jaundiced heart" [4]. The jaundiced heart is also characterized by defective vascular reactivity attributed to altered beta-adrenergic receptor signaling [6], membrane

\footnotetext{
* Correspondence: ywf808@yeah.net

+ Contributed equally

${ }^{2}$ Department of Anesthesia and Intensive Care, Eastern Hepatobiliary Surgical

Hospital, the Second Military Medical University, Shanghai, China

Full list of author information is available at the end of the article
}

fluidity, and down regulation of cardiac beta-adrenoceptor density and affinity [7].

Propofol is a widely employed intravenous anesthetic used to induce and maintain anesthesia. It is characterized by rapid onset/offset of effect and rapid elimination from the body $[8,9]$. However, propofol can also induce cardiovascular depression, manifested primarily by decreased arterial blood pressure [10] due to inhibition of the sympathetic nervous system [11], a negative inotropic effect [12], and reduced preload [13].

The effect of propofol on myocardial performance in patients with obstructive jaundice is unclear. Therefore, in the present study, 7-day bile duct ligation (BDL) was used as a model of obstructive jaundice to evaluate the effect of propofol on cardiac function in vivo. In ex vivo experiments, the direct effects of propofol on the isolated

\section{Biomed Central}

(c) 2011 Ren et al; licensee BioMed Central Ltd. This is an Open Access article distributed under the terms of the Creative Commons Attribution License (http://creativecommons.org/licenses/by/2.0), which permits unrestricted use, distribution, and reproduction in any medium, provided the original work is properly cited. 
heart of BDL rats were assessed to exclude the vasodilator effect of propofol and the associated neurohormonal adaptation in vivo $[14,15]$.

\section{Methods}

Animals

This study protocol was approved by the Institutional Animal Care and Use Committee at the Second Military Medical University. Male Sprague-Dawley rats (250-300 g) were housed in a temperature and humidity-controlled environment with a 12 -h light dark cycle. The rats received unlimited access to water and food. Food was removed from the cage 16 hours before initiating the experiments.

\section{Procedures}

Forty rats were randomly allocated into two study groups: 20 underwent the BDL procedure, and 20 underwent a sham operation (control), according to Lee [16]. Rats were anesthetized with pentobarbital sodium $(40 \mathrm{mg} / \mathrm{kg}$ by intraperitoneal [i.p.] administration). After opening the abdominal cavity, the bile duct was ligated at a point proximal to the hilus and a point immediately distal to the entry of the bile duct into the duodenum. The bile duct was then severed between the ligatures. The sham operation was carried out in a similar manner, but did not include ligating and severing the bile duct. Seven days after the BDL and sham procedures, blood was obtained to assess total bilirubin and alanine aminotransferase levels.

\section{In vivo experiment}

For the in vivo experiments, all surgical procedures were performed under sterile conditions. On the seventh postoperative day, rats (BDL group, $n=10$; sham-operated control group, $n=10$ ) were anesthetized with sodium pentobarbital (40 mg/kg i.p.). After tracheotomy and tracheal intubation, mechanical ventilation (room air at 6070 breaths/min) was provided with a Harvard Apparatus Rodent Respirator (Harvard Apparatus, Boston, MA). A heating pad was placed under the animal to keep the rectal temperature at $36^{\circ} \mathrm{C} \pm 1^{\circ} \mathrm{C}$. A $1-\mathrm{cm}$ midline incision was made in the neck, and the right common carotid artery was exposed. A polyethylene cannula was inserted through the artery to the left ventricle. To monitor intraventricular pressure, the cannula was connected to a pressure transducer (RM6240B type; Chengdu Instrument Corp., China). A cannula connected to a microinfusion pump (Graseby 3500; Graseby Medical Ltd., Watford, UK) via a three-port switch was placed in the left jugular vein for propofol administration. After a 30min stabilization period, rats received an intravenous injection of propofol (Diprivan 2\%, AstraZeneca UK Ltd UK) The dose range used in our study encompassed the
$50 \%$ effective dose for propofol as reported by Carmichael et al. [17]. Doses of 300, 600 and $900 \mu \mathrm{g} / \mathrm{kg}$ per minute of propofol were administered by infusion (15 min each dose) to generate dose-response curves for heart rate (HR), left ventricular end-systolic pressure (LVESP), and maximal rate for left ventricular pressure rise and declining $\left( \pm \mathrm{dP} / \mathrm{dt}_{\max }\right)$. HR and cardiac function indices were determined at the point of maximum response for each propofol dose.

\section{Ex vivo experiment}

Langendorff heart preparation (ML870B2 AD Instruments Ltd, Shanghai, China) was used to evaluate the effects of propofol on cardiac performance. The rats (BDL group, $n=10$; sham-operated control group, $n=10$ ) were anesthetized with sodium pentobarbital (40 mg/kg i.p.). The heart was removed from the thoracic cavity and placed in ice-cold Krebs-Henseleit bicarbonate buffer $(\mathrm{pH}$ 7.4) containing heparin sodium. The heart was rapidly mounted on a Langendorff perfusion system via the aorta. A cardiac catheter, with a latex saccule at the tip, was inserted from a cut in the left auricle of the left atrium to the left ventricle. The saccule was filled with water to maintain the left ventricular end-diastolic pressure (LVEDP) at 6 to $8 \mathrm{mmHg}$. The other end of the catheter was connected to a pressure transducer (MLT844; Shanghai, China). The average surrounding pressure was 70 to $80 \mathrm{mmHg}$. The perfusion medium was a modified KrebsHenseleit bicarbonate buffer gassed with 95\% O2 and 5\% $\mathrm{CO}_{2}$ at atmospheric pressure and maintained at $37.5^{\circ} \mathrm{C}$. The buffer was composed of $118 \mathrm{mmol} / \mathrm{L} \mathrm{NaCl}, 4.7 \mathrm{mmol} /$ $\mathrm{L} \mathrm{KCl}, 1.2 \mathrm{mmol} / \mathrm{L} \mathrm{KH} \mathrm{PO}_{4}, 25 \mathrm{mmol} / \mathrm{L} \mathrm{NaHCO}$, $2.5 \mathrm{mmol} / \mathrm{L} \mathrm{CaCl} 2,11.0 \mathrm{mmol} / \mathrm{L}$ glucose, $0.5 \mathrm{mmol} / \mathrm{L}$ EDTA- $\mathrm{Na}_{2}$ and $1.2 \mathrm{mmol} / \mathrm{L} \mathrm{MgSO}_{4}$. Recorded parameters included HR, LVESP, LVEDP, (and $\pm \mathrm{dP} / \mathrm{dt}_{\text {max }}$ ). Effects of propofol $(12.5,25$, and $50 \mu \mathrm{mol} / \mathrm{L})$ were tested using a method described by Jacob et al [18]. In rats that underwent 3-day BDL, Jacob [18] showed impaired basal cardiac contractility and reduced left intraventricular pressure using two preparations of pithed rats and isolated functioning hearts. When the aortic flow and left ventricular pressure were stabilized, data were acquired for 30 consecutive seconds prior to drug testing. Each drug concentration was tested for a period of $15 \mathrm{~min}$.

\section{Statistical methods}

Data analysis was performed with Prism version 4.0 (GraphPad Software; San Diego, CA). Responses of cardiac function to propofol are expressed as mean \pm standard error of the mean (SEM) relative to baseline values (percentage). Group results were compared by Student's unpaired t-test or the chi-square test. In vivo and ex vivo myocardial performance data were compared by two-way repeated measure analysis of variance (ANOVA) followed 
by the post hoc Bonferroni test. A P-value of $<0.05$ was considered significant.

\section{Results}

Serum total bilirubin and alanine transaminase in the BDL group were significantly higher than those in the shamoperated control group (total bilirubin, $1.4 \pm 0.2 \mathrm{vs}$ $158.7 \pm 10.8 \mathrm{mM} / \mathrm{L}$, respectively; alanine transaminase, $28.1 \pm 1.9$ vs $150.0 \pm 14.2 \mathrm{IU} / \mathrm{L}$ respectively $)(\mathrm{P}<0.01)$.

\section{In vivo cardiac function}

The baseline contractility and lusitropy (LVESP and \pm $\left.\mathrm{dP} / \mathrm{dt}_{\max }\right)$ of the BDL group were higher than those of the sham-operated controls $(\mathrm{P}<0.05)$, although LVEDP did not differ significantly between the two study groups (Table 1). Blood pressure decreased in the BDL group after propofol administration but there was no significant difference compared with blood pressure after the same propofol concentrations in the control group. At an infusion rate of 300 to $600 \mu \mathrm{g} / \mathrm{kg}$ per min, propofol decreased HR, LVESP, and $\pm \mathrm{dP} / \mathrm{dt}_{\max }$, but not LVEDP. The decreases in HR, LVESP, and $\pm \mathrm{dP} / \mathrm{dt}_{\max }$ were dosedependent in both experimental groups (Figure 1). At $900 \mu \mathrm{g} / \mathrm{kg}$ per min, the inhibitory effects of propofol on cardiac performance were greater in the BDL group than in the sham-operated control group $(\mathrm{P}<0.05)$ (Figure 1).

\section{Ex vivo cardiac function}

At baseline, LVESP, $\pm \mathrm{dP} / \mathrm{dt}$, LVEDP and HR were significantly lower in the BDL group than in the control group $(\mathrm{P}<0.05)$ (table 2). At 12.5 and $50 \mu \mathrm{mol} / \mathrm{L}$, propofol significantly decreased HR, LVESP, and $\pm \mathrm{dP} / \mathrm{dt}_{\max }$, but increased LVEDP. The dose-dependent decrease in response appeared to be more pronounced in the BDL group, and this difference was significant at $50 \mu \mathrm{mol} / \mathrm{L}$ of propofol $(\mathrm{P}<0.01)$ (Figure 2).

\section{Discussion}

In the present study, we could not confirm impaired cardiac performance in a rat model of obstructive jaundice because the in vivo and ex vivo results were inconsistent. However, an important and novel finding is that the inhibitory effects of propofol on myocardial function were comparable in rats that underwent BDL and rats that underwent the sham operation at low and intermediate doses $(12.5$ and $25 \mu \mathrm{mol} / \mathrm{L})$. At the highest dose of propofol tested $(50 \mu \mathrm{mol} / \mathrm{L})$, stronger effects on cardiac function were observed in rats with obstructive jaundice.

A propofol concentration of 2 to $4 \mu \mathrm{M}$ was clinically relevant according to a previous study [19], and researchers proved that higher than $>10 \mu \mathrm{M}$ propofol in vitro might cause cardiovascular depression [20]. To compare the hemodynamic effects of propofol between cholestatic rat hearts and controls, we use d relatively high concentrations $(12.5,25$, and $50 \mu \mathrm{mol} / \mathrm{L})$ of propofol ex vivo because propofol at $<10 \mu \mathrm{M}$ did not suppress the KATP channel or display a myocardial depression effect [21]. The present study did not confirm our hypothesis that propofol depresses myocardial performance in the jaundiced heart compared with the normal, healthy heart. This finding may be attributed to a number of factors. First, most animal and human studies have shown that propofol induces dose-dependent cardiovascular depression. Furthermore, clinically relevant concentrations of propofol do not significantly depress myocardial contractility and evidence suggests that its pharmacological properties may be due in part to enhanced sensitivity of the myofilaments to $\mathrm{Ca}^{2+}$, despite reduced uptake of $\mathrm{Ca}^{2+}$ uptake into the sarcoplasmic reticulum $[22,23]$. Moreover, propofol is a cardioprotective agent and may protect the myocardium from injury such as that caused by ischemia-reperfusion [24,25]. Inhibition of the mitochondrial permeability transition pore is a recently reported mechanism underlying the protective action of propofol on the myocardium $[24,26]$. In addition, accumulation of bile acids is a causative factor for jaundiced heart [5]. Bile acids exert negative chronotropic and inotropic effects on the heart via mitochondrial damage $[12,27]$. These factors especially the enhanced sensitivity of the myofilaments to $\mathrm{Ca}^{2+}$ and the inhibition of the mitochondrial permeability transition pore, may protect against cardiovascular depression and account for the minimal responsiveness of BDL-treated rats to low and intermediate concentrations of propofol.

Another interesting observation was the opposite in vivo and ex vivo results of basal cardiac contractility in the BDL group. In the ex vivo experiments, hearts from the BDL-treated rats exhibited impaired contractility and a reduction in the maximum pressure in the left ventricle, whereas BDL-treated rats showed

Table 1 In vivo baseline heart rate and cardiac function in the BDL group and sham control group

\begin{tabular}{|c|c|c|c|c|c|c|}
\hline & HR (bpm) & LVESP (mmHg) & LVEDP (mmHg) & $+\mathrm{dP} / \mathrm{dt}_{\max }\left(\mathrm{mmHg} \mathrm{s}^{-1}\right)$ & $-\mathrm{dP} / \mathrm{dt}_{\max }\left(\mathrm{mmHg} \mathrm{s}^{-1}\right)$ & $\mathrm{ABP}(\mathrm{mmHg})$ \\
\hline SO & $355.5 \pm 12.7$ & $110.1 \pm 4.3$ & $3.7 \pm 0.4$ & $2173.6 \pm 82.3$ & $1249.7 \pm 92.6$ & $105 \pm 17$ \\
\hline $\mathrm{BDL}$ & $311.3 \pm 16.7^{*}$ & $127.2 \pm 6.4^{*}$ & $4.5 \pm 0.5$ & $3288.7 \pm 112.3^{*}$ & $2512.8 \pm 132.5^{*}$ & $109 \pm 13$ \\
\hline
\end{tabular}

( $n=10$ in each group)

Values are means $\pm \mathrm{SEM} ; n$, sample size; SO, sham-operated; BDL, bile duct ligation; HR, heart rate; LVESP, left ventricular end-systolic pressure; LVEDP, left ventricular end-diastolic pressure; $\pm \mathrm{dP} / \mathrm{dt}_{\max }$, maximal rate for left ventricular pressure rising and declining; $A B P$, arterial blood pressure.

* $\mathrm{P}<0.05$ vs sham controls. 


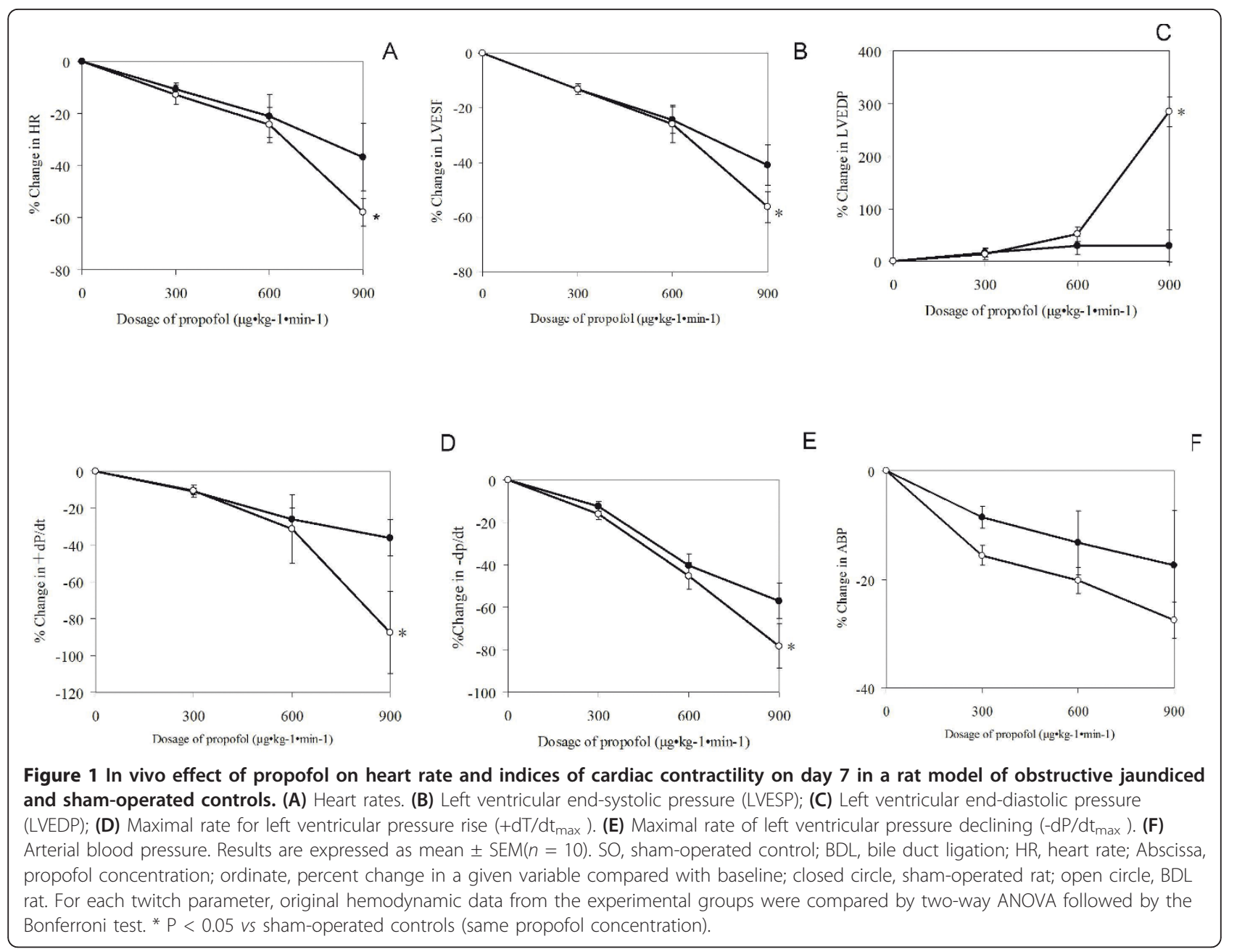

significantly increased LVSEP, $+\mathrm{dP} / \mathrm{dt}_{\max }$ and $-\mathrm{dP} / \mathrm{dt}_{\max }$ in vivo. The mechanism underlying this phenomenon is unclear, but may involve neural or humoral adaptations. Dabagh [28] reported increased concentrations of norepinephrine and epinephrine during the development of cholestasis. Poo [29] found elevated renin and angiotensin II at 1 week after establishment of obstructive jaundice in rats. In our in vivo experiments, increased LVSEP, $+\mathrm{dP} / \mathrm{dt}_{\max }$ and $-\mathrm{dP} / \mathrm{dt}_{\max }$, were associated with myocardial contractility, suggesting up regulation of the sympathetic nervous system. In addition, LVEDP which directly relates to the cardiac preload might remain unchanged possibly not owing to the depletion of body fluid in obstructive jaundice [30,31]. However, the lower heart rate may be caused in part by accumulated bile acids, which impair cardiac function by affecting calcium uptake from the sarcoplasmic reticulum [32,33]. Recent research has focused on the overproduction of nitric oxide, which results in bradycardia after BDL [34,35]. Despite enhanced cardiac contractility in vivo, our experiment showed that a high dose of propofol produced stronger inhibition of cardiac function in BDL-treated rats, unmasking latent cardiac dysfunction. These results are consistent with those of previous studies reporting that BDL-treated rats show hemodynamic instability [5].

Table 2 Ex vivo baseline heart rate and cardiac function in the BDL group and the sham control group

\begin{tabular}{llllll}
\hline & HR $(\mathbf{b p m})$ & LVESP $(\mathbf{m m H g})$ & LVEDP $(\mathbf{m m H g})$ & $+\mathbf{d P} / \mathbf{d t}_{\max }(\mathbf{m m H g ~ s}-1)$ & $-\mathbf{d P}_{\mathbf{d d t}}$ max $(\mathbf{m m H g ~ s}-1)$ \\
\hline $\mathrm{SO}(\mathrm{n}=10)$ & $254.5 \pm 19.5$ & $112.5 \pm 6.9$ & $4.8 \pm 0.5$ & $1469.2 \pm 157.4$ & $1117.5 \pm 70.0$ \\
$\mathrm{BDL}(\mathrm{n}=10)$ & $201.3 \pm 13.5^{*}$ & $92.4 \pm 5.4^{*}$ & $7.4 \pm 0.3^{*}$ & $1146.0 \pm 64.2^{*}$ & $954.3 \pm 103.7^{*}$ \\
\hline
\end{tabular}

Values are means $\pm \mathrm{SEM} ; n$, sample size; SO, sham operated; BDL, bile duct ligation; HR, heart rate; LVESP, left ventricular end-systolic pressure; LVEDP, left ventricular end-diastolic pressure; $\pm \mathrm{dP} / \mathrm{dt}_{\max }$, maximal rate for left ventricular pressure rising and declining.

* $\mathrm{P}<0.05$ vs sham controls. 


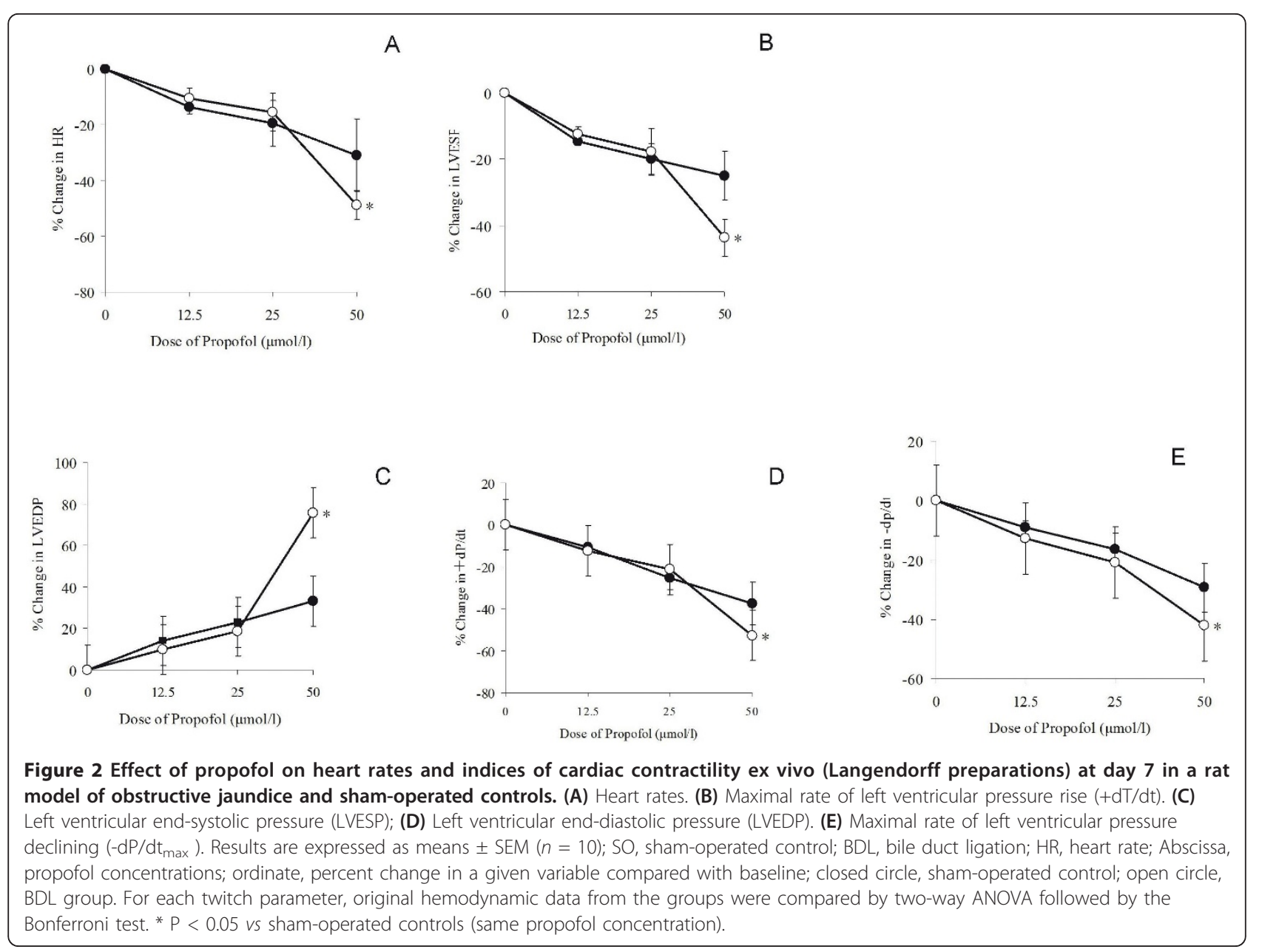

There are also limitations in our study. To assess left ventricular inotropism, three load-dependent indices of left ventricular contractility (LVESP, LVEDP, and $\pm \mathrm{dP}$ / $\mathrm{dt}_{\max }$ ) were used. It must be underscored that these indices may also be influenced by left ventricular loading conditions [36]. Load-independent indices of left ventricular contractility, such as construction of pressurevolume curves in both systole and diastole would greatly enhance the validity and interpretation of our results. It would enable more specific measurement of the left ventricular performance independent of both loading conditions and HR [37]. Thus, the data of our study must be interpreted with caution when using propofol at mild to intermediate doses in obstructive jaundice.

\section{Conclusions}

In conclusion, the present study demonstrates that obstructive jaundice impairs cardiac function ex vivo but enhances cardiac performance in vivo. Propofol depresses cardiac parameters at low and intermediate doses to a similar degree in BDL-treated and shamoperated rats. However, at a high dose, propofol may cause exaggerated cardiac depression in jaundiced rats. Our study suggestes that propofol is a safe alternative anesthetic agent in patients with obstructive jaundice and normal cardiac function at low and intermediate doses.

\section{Acknowledgements}

We gratefully acknowledge the National Natural Science Foundation Committee of China (Grant No. 81072625, 81170427) and Shanghai Municipal Education Commission Foundation (Grant No.11ZZ73) for their financial support.

\section{Author details}

'Department of Anesthesia, Putuo Hospital, Shanghai, China. ${ }^{2}$ Department of Anesthesia and Intensive Care, Eastern Hepatobiliary Surgical Hospital, the Second Military Medical University, Shanghai, China. ${ }^{3}$ Department of Anesthesiology, Shanghai First Maternity and Infant Hospital, Tongji University School of Medicine, Shanghai, China. ${ }^{4}$ Department of Anaesthesiology, University of Hong Kong, Hong Kong, China.

\section{Authors' contributions}

HR: data mining and analysis in fulfillment of his MD thesis. LY and ZL: idea, experimental design and part of animal studies. CC and KT: conception and help with statistics. CC: conception writing of the paper. JS and WC: ex vivo experiment. WY: idea, experimental design and part of animal studies. All authors read and approved the final version of the manuscript. 


\section{Competing interests}

The authors declare that they have no competing interests.

Received: 7 June 2011 Accepted: 28 December 2011

Published: 28 December 2011

\section{References}

1. Dixon JM, Armstrong CP, Duffy SW, Davies GC: Factors affecting morbidity and mortality after surgery for obstructive jaundice: a review of 373 patients. Gut 1983, 24(9):845-852

2. Wait RB, Kahng KU: Renal failure complicating obstructive jaundice. Am J Surg 1989, 157(2):256-263.

3. Green J, Better OS: Systemic hypotension and renal failure in obstructive jaundice-mechanistic and therapeutic aspects. J Am Soc Nephrol 1995, 5(11):1853-1871.

4. Lumlertgul D, Boonyaprapa S, Bunnachak D, Thanachaikun N, Praisontarangkul OA, Phornphutkul K, Keoplung M: The jaundiced heart: evidence of blunted response to positive inotropic stimulation. Ren Fail 1991, 13(1):15-22.

5. Green J, Beyar R, Sideman S, Mordechovitz D, Better OS: The "jaundiced heart": a possible explanation for postoperative shock in obstructive jaundice. Surgery 1986, 100(1):14-20.

6. Ma Z, Miyamoto A, Lee SS: Role of altered beta-adrenoceptor signal transduction in the pathogenesis of cirrhotic cardiomyopathy in rats. Gastroenterology 1996, 110(4):1191-1198.

7. Gazawi H, Ljubuncic P, Cogan U, Hochgraff E, Ben-Shachar D, Bomzon A: The effects of bile acids on beta-adrenoceptors, fluidity, and the extent of lipid peroxidation in rat cardiac membranes. Biochem Pharmacol 2000, 59(12):1623-1628.

8. Lange H, Stephan H, Rieke H, Kellermann M, Sonntag H, Bircher J: Hepatic and extrahepatic disposition of propofol in patients undergoing coronary bypass surgery. Br J Anaesth 1990, 64(5):563-570.

9. Hughes MA, Glass PS, Jacobs JR: Context-sensitive half-time in multicompartment pharmacokinetic models for intravenous anesthetic drugs. Anesthesiology 1992, 76(3):334-341.

10. Marik PE: Propofol: therapeutic indications and side-effects. Curr Pharm Des 2004, 10(29):3639-3649.

11. Ebert TJ: Sympathetic and hemodynamic effects of moderate and deep sedation with propofol in humans. Anesthesiology 2005, 103(1):20-24.

12. Li YC, Ridefelt P, Wiklund L, Bjerneroth G: Propofol induces a lowering of free cytosolic calcium in myocardial cells. Acta Anaesthesiol Scand 1997, 41(5):633-638

13. Bilotta F, Fiorani L, La Rosa I, Spinelli F, Rosa G: Cardiovascular effects of intravenous propofol administered at two infusion rates: a transthoracic echocardiographic study. Anaesthesia 2001, 56(3):266-271.

14. Yamanoue T, Brum JM, Estafanous FG: Vasodilation and mechanism of action of propofol in porcine coronary artery. Anesthesiology 1994, 81(2):443-451

15. Muzi M, Berens RA, Kampine JP, Ebert TJ: Venodilation contributes to propofol-mediated hypotension in humans. Anesth Analg 1992, 74(6):877-883

16. Lee SS, Pak JM, Medlicott SM, Bomzon A: Vasodilatory responses of isolated arteries of cirrhotic rats. Clin Sci (Lond) 1995, 89(3):227-232.

17. Carmichael FJ, Crawford MW, Khayyam N, Saldivia V: Effect of propofol infusion on splanchnic hemodynamics and liver oxygen consumption in the rat. A dose-response study. Anesthesiology 1993, 79(5):1051-1060.

18. Jacob G, Nassar N, Hayam G, Ben-Haim S, Edoute Y, Better OS, Bomzon A: Cardiac function and responsiveness to beta-adrenoceptor agonists in rats with obstructive jaundice. Am J Physiol 1993, 265(2 Pt 1):G314-320

19. Wu MH, Su MJ, Sun SS: Comparative direct electrophysiological effects of propofol on the conduction system and ionic channels of rabbit hearts. BrJ Pharmacol 1997, 121(4):617-624.

20. Kokita N, Hara A, Abiko Y, Arakawa J, Hashizume H, Namiki A: Propofol improves functional and metabolic recovery in ischemic reperfused isolated rat hearts. Anesth Analg 1998, 86(2):252-258.

21. Kawano T, Oshita S, Tsutsumi Y, Tomiyama Y, Kitahata H, Kuroda $Y$, Takahashi A, Nakaya Y: Clinically relevant concentrations of propofol have no effect on adenosine triphosphate-sensitive potassium channels in rat ventricular myocytes. Anesthesiology 2002, 96(6):1472-1477.
22. Kanaya N, Murray PA, Damron DS: Propofol increases myofilament Ca2+ sensitivity and intracellular $\mathrm{pH}$ via activation of $\mathrm{Na}+-\mathrm{H}+$ exchange in rat ventricular myocytes. Anesthesiology 2001, 94(6):1096-1104.

23. Sprung J, Ogletree-Hughes ML, McConnell BK, Zakhary DR, Smolsky SM, Moravec CS: The effects of propofol on the contractility of failing and nonfailing human heart muscles. Anesth Analg 2001, 93(3):550-559.

24. Javadov SA, Lim KH, Kerr PM, Suleiman MS, Angelini GD, Halestrap AP: Protection of hearts from reperfusion injury by propofol is associated with inhibition of the mitochondrial permeability transition. Cardiovasc Res 2000, 45(2):360-369.

25. Vendemiale G, Grattagliano I, Lupo L, Memeo V, Altomare E: Hepatic oxidative alterations in patients with extra-hepatic cholestasis. Effect of surgical drainage. J Hepatol 2002, 37(5):601-605.

26. Oliveira PJ, Rolo AP, Seica R, Santos MS, Palmeira CM, Moreno AJ: Reduction in cardiac mitochondrial calcium loading capacity is observable during alpha-naphthylisothiocyanate-induced acute cholestasis: a clue for hepatic-derived cardiomyopathies? Biochim Biophys Acta 2003, 1637(1):39-45

27. Schroder O, Rathner W, Caspary WF, Stein J: Bile acid-induced increase of rat colonic apical membrane fluidity and proton permeability. $Z$ Gastroenterol 1996, 34(6):365-370

28. Dabagh K, Said O, Lebrec D, Bomzon A: Down-regulation of vascular alpha1-adrenoceptors does not account for the loss of vascular responsiveness to catecholamines in experimental cholestasis. Liver 1999, 19(3):193-198.

29. Poo JL, Estanes A, Pedraza-Chaverri J, Cruz C, Uribe M: Effects of ursodeoxycholic acid on hemodynamic and renal function abnormalities induced by obstructive jaundice in rats. Ren Fail 1995, 17(1):13-20.

30. Gallardo JM, Padillo J, Martin-Malo A, Mino G, Pera C, Sitges-Serra A: Increased plasma levels of atrial natriuretic peptide and endocrine markers of volume depletion in patients with obstructive jaundice. $\mathrm{Br} J$ Surg 1998, 85(1):28-31.

31. Padillo FJ, Rodriguez M, Gallardo JM, Andicoberry B, Naranjo A, MartinMalo A, Mino G, Sitges-Serra A, Pera-Madrazo C: Preoperative assessment of body fluid disturbances in patients with obstructive jaundice. World J Surg 1999, 23(7):681-687, discussion 687

32. Gorelik J, Harding SE, Shevchuk Al, Koralage D, Lab M, de Swiet M, Korchev $Y$, Williamson C: Taurocholate induces changes in rat cardiomyocyte contraction and calcium dynamics. Clin Sci (Lond) 2002, 103(2):191-200.

33. Williamson C, Gorelik J, Eaton BM, Lab M, de Swiet M, Korchev Y: The bile acid taurocholate impairs rat cardiomyocyte function: a proposed mechanism for intra-uterine fetal death in obstetric cholestasis. Clin Sci (Lond) 2001, 100(4):363-369.

34. Gaskari SA, Mani AR, Ejtemaei-Mehr S, Namiranian K, Homayoun $H$, Ahmadi $H$, Dehpour AR: Do endogenous opioids contribute to the bradycardia of rats with obstructive cholestasis? Fundam Clin Pharmacol 2002, 16(4):273-279.

35. Mani AR, Nahavandi A, Moosavi M, Safarinejad R, Dehpour AR: Dual nitric oxide mechanisms of cholestasis-induced bradycardia in the rat. Clin Exp Pharmacol Physiol 2002, 29(10):905-908.

36. Jianhui L, Rosenblatt-Velin N, Loukili N, Pacher P, Feihl F, Waeber B, Liaudet $L$ : Endotoxin impairs cardiac hemodynamics by affecting loading conditions but not by reducing cardiac inotropism. Am J Physiol Heart Circ Physiol 2010, 299(2):H492-501.

37. Pacher $P$, Nagayama T, Mukhopadhyay $P$, Bátkai $S$, Kass DA: Measurement of cardiac function using pressure-volume conductance catheter technique in mice and rats. Nat Protoc 2008, 3(9):1422-34.

\section{Pre-publication history}

The pre-publication history for this paper can be accessed here: http://www.biomedcentral.com/1471-230X/11/144/prepub

\section{doi:10.1186/1471-230X-11-144}

Cite this article as: Ren et al:. In vivo and ex vivo effects of propofol on myocardial performance in rats with obstructive jaundice. $B M C$ Gastroenterology 2011 11:144. 